\title{
NOx, Soot, and Fuel Consumption Predictions under Transient Operating Cycle for Common Rail High Power Density Diesel Engines
}

\author{
N. H. Walke, ${ }^{1}$ M. R. Nandgaonkar, ${ }^{2}$ and N. V. Marathe ${ }^{1}$ \\ ${ }^{1}$ The Automotive Research Association of India, Pune, Maharashtra 411038, India \\ ${ }^{2}$ Department of Mechanical Engineering, College of Engineering Pune, Pune, Maharashtra 411005, India \\ Correspondence should be addressed to N. H. Walke; walke.edl@araiindia.com
}

Received 5 December 2015; Revised 21 February 2016; Accepted 28 February 2016

Academic Editor: Constantine D. Rakopoulos

Copyright ( $\odot 2016$ N. H. Walke et al. This is an open access article distributed under the Creative Commons Attribution License, which permits unrestricted use, distribution, and reproduction in any medium, provided the original work is properly cited.

Diesel engine is presently facing the challenge of controlling NOx and soot emissions on transient cycles, to meet stricter emission norms and to control emissions during field operations. Development of a simulation tool for NOx and soot emissions prediction on transient operating cycles has become the most important objective, which can significantly reduce the experimentation time and cost required for tuning these emissions. Hence, in this work, a OD comprehensive predictive model has been formulated with selection and coupling of appropriate combustion and emissions models to engine cycle models. Selected combustion and emissions models are further modified to improve their prediction accuracy in the full operating zone. Responses of the combustion and emissions models have been validated for load and "start of injection" changes. Model predicted transient fuel consumption, air handling system parameters, and NOx and soot emissions are in good agreement with measured data on a turbocharged high power density common rail engine for the "nonroad transient cycle" (NRTC). It can be concluded that 0D models can be used for prediction of transient emissions on modern engines. How the formulated approach can also be extended to transient emissions prediction for other applications and fuels is also discussed.

\section{Introduction}

Diesel engine has distinct advantages of better fuel economy, higher torque back-up, and high reliability over the other prime movers. For off-road and commercial vehicles, mostly diesel engine is used as the prime mover and it will maintain its dominance for many years to come. However, these engines require very complex after-treatment devices to meet stringent emission targets for NOx and soot, on transient legislative cycles as well as on different transient cycles representing field operations. There are differences in NOx and soot emissions between operation under transient condition with speed or load increase and their corresponding steady state speed-load points [1]. Hence, to meet transient cycle emissions with low cost after-treatment devices as well as to achieve lower emissions in real operations, engines are required to be specifically optimised for transient emissions. For prediction of transient emissions, interactions and responses of different combustion related systems are required to be considered; hence quasistationary steady state based models with correction for transient conditions fail to predict transient emissions [2]. Engines optimised using steady state emission prediction models may not give lower emissions in transient operating conditions and further optimisations for transient emissions require extensive experimentations. As such, transient soot and NOx prediction model will be of great help to reduce experimentation time and cost. Such a prediction tool will also help to achieve optimum configuration, which may not be otherwise possible with only experimentations due to hardware limitations. Study of pollutants emissions during transient operation with development of suitable models is the most important objective for the future and has received a little attention so far $[3,4]$. Hence, in this work, a case study has been taken to formulate a comprehensive model for NOx and soot 
predictions and assessment of the model prediction results on a transient cycle.

While selecting the simulation approach, tuning cost and time become extremely important when a large number of cycles for complete engine are to be evaluated. 3D models demand large amount of computing power and time; also their benefit lowers due to requirement of empirical correlations [5]. Hence, OD multizone models are used for these analyses; however the majority of available $0 \mathrm{D}$ transient models have not included emissions prediction [1]. Generally, diagnostic models prepared by statistical processing on experimental data are used for analyses of transient emissions. Diagnostic combustion model, by obtaining "rate of heat release" (RoHR) by statistical parameterization of Wiebe's function, requires change in statistical function parameters with change in load to predict RoHR $[6,7]$. NOx and soot diagnostic simulation models prepared from regression of experimental data [8] or by neural network trained thermodynamics mimicked model [4] require compensations for transient operations. Additionally, such a diagnostic model will have prediction applicability only for the engine on which that particular empirical model is prepared. Empirical model also requires large amount of engine test data and regression efforts. It is also experienced that the commercially available software for transient emission analysis requires extensive efforts for tuning constants to match with the experimental data, throughout the operating zone. On the contrary, predictive models do not require test data for model formulation and do not require compensations for transient operation or for any particular operation zone. Hence such models can be used as a design tool; however appropriateness of $0 \mathrm{D}$ models as a tool for prediction of transient emissions of modern engines is required to be assessed.

Hence, in this work, a $0 \mathrm{D}$ comprehensive predictive model has been formulated with selection and coupling of appropriate combustion and emissions models to engine cycle models. Selected combustion and emissions models are further evaluated for their prediction accuracies in the full operating zone of modern turbocharged high pressure common rail engines, since modern engines significantly differ in power density and fuel injection pressures compared to the previous generation engines. Combustion and soot emission models are modified and model constants are determined such that acceptable model prediction accuracy is achieved in the entire operating range with a single set of constants.

"Nonroad transient cycle" (NRTC), applicable for engines used in agricultural and construction equipment, has been selected for model validation as a case study since this is the most cost sensitive area dependent fully on diesel engines. It is expected that the values identified in the model validation for most of the constants should be as it is applicable for the same category of engines (off-road and on-road medium duty) for analysis of trends. Also it is expected that for the same category of engines, due to change in intake, exhaust, and combustion system configuration, values of constants for intake system restriction, exhaust system restriction, and emission scaling should not be required to be changed significantly and for quantitative analysis these constants

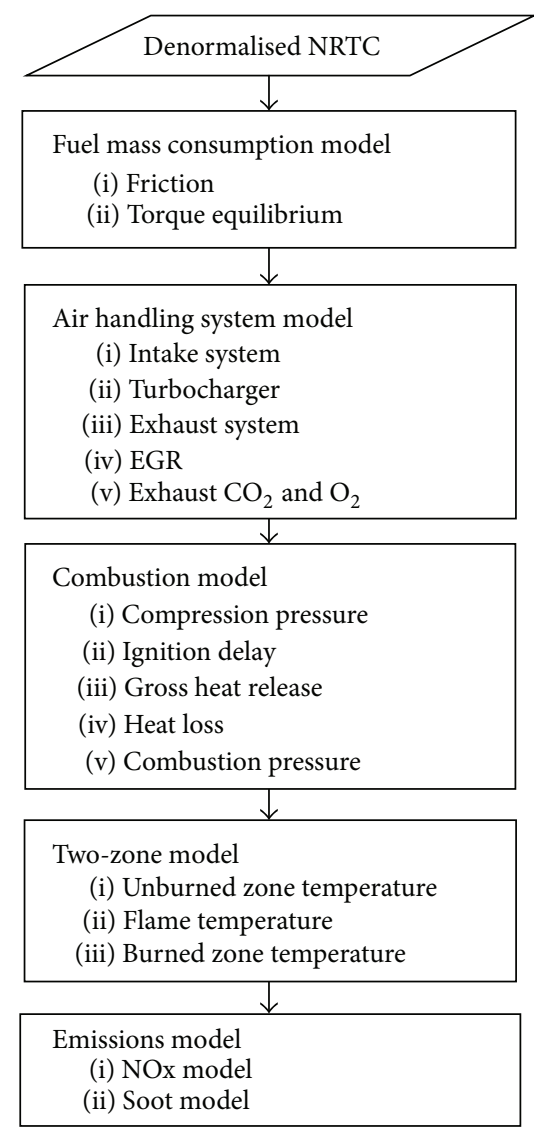

FIGURE 1: Comprehensive model structure.

would require minor adjustments based on few experimental points. The constants which would require change in their values are discussed in Section 3.

\section{Materials and Methodology}

2.1. Model Formulation. The formulated comprehensive model consists of torque equilibrium, friction, air handling, combustion, and emissions models. Coupling of these models and submodels used in each of these models are shown in the comprehensive model structure (Figure 1). Fuel consumption is predicted using torque equilibrium and modified friction submodels. Air handling system parameters are predicted using quasisteady model formulated with a new approach. Single-zone combustion model and two-zone emissions models are used for soot and NOx predictions.

2.1.1. Fuel Mass Consumption Model. Generally, fuel consumption on a transient cycle is derived from measured data (e.g., [8]). However, being a predictive tool, this model estimates instantaneous fuel mass consumption from total torque required to be produced by the engine, with input of the transient operating cycle. This total torque is addition of operating cycle torque demand $\left(\tau_{\text {cycle }}\right)$, frictional torque $\left(\tau_{\mathrm{fr}}\right)$, and torque required for engine acceleration, as shown in (1). " $\tau_{\mathrm{fr}}$ " is estimated using modified "friction mean effective 
pressure" (FMEP) model, which is based on FMEP model in [9]. Modified FMEP model uses "brake mean effective pressure" (BMEP) as one of the model inputs, as shown in (3):

$$
\begin{aligned}
\dot{m}_{\text {fuel }} & =\frac{C_{\mathrm{IP}} \pi N\left(\tau_{\text {cycle }}+\tau_{\text {fr }}+G_{E}(d \omega / d t)\right)}{30000}, \\
\tau_{\text {fr }} & =\frac{\operatorname{FMEP}_{m} A_{\text {pist }} r n_{\text {cyl }}}{2 \pi}, \\
\operatorname{FMEP}_{m} & =\alpha+\beta_{1 m} e^{\beta_{f} \text { BMEP }}+\gamma \bar{u}_{\text {pist }} .
\end{aligned}
$$

The following are the fuel consumption model constants derived by experimental investigations:

$$
\begin{aligned}
C_{\mathrm{IP}} & =5.0358 \times 10^{-5}, \\
\alpha & =4.5 \times 10^{4}, \\
\beta_{1 m} & =3.09 \times 10^{4}, \\
\beta_{1 f} & =5.84 \times 10^{-7}, \\
\gamma & =1.76 \times 10^{4} .
\end{aligned}
$$

2.1.2. Air Handling System (AHS) Model. AHS parameters are determined as per the flow chart shown in Figure 2. In a transient operation, there will be a time lag in charge air handling between compressor and turbine. This delay is due to charge air travel through after-cooler connecting pipes and further due to in-cylinder process from IVC to EVO. Since considered category of engines has low operating speed range, this lag would not change significantly with change in speed; hence this lag is assumed as constant throughout the transient cycle. Assuming typical air travel path and incylinder process lag of $280^{\circ} \mathrm{CA}$ (from IVC to EVO), a total lag of $100 \mathrm{~ms}$ has been considered. AHS model is based on quasisteady cylinder filling and emptying approach. The assumption of quasisteady flow does not usually introduce a major error, if calculation proceeds in a series of very small time steps [10]. Hence, AHS parameters are determined over a very small time step of $10 \mathrm{~ms}$. Transient cycle speed-torque demand and fuel mass flow rate data available at $1 \mathrm{~s}$ interval are interpolated and used as inputs to this model.

To begin exhaust side calculations, "turbine mass flow parameter" $\left(\mathrm{MFP}_{\text {trb }}\right)$ is calculated using "exhaust manifold pressure" $\left(p_{b_{-} \text {trb }}\right)$ from the previous time step. "Exhaust mass flow rate" $\left(\dot{m}_{\text {exh }}\right)$ is calculated with previous time step "air mass flow rate" $\left(\dot{m}_{\text {air }}\right)$ and current time step "fuel mass flow rate" ( $\left.\dot{m}_{\text {fuel }}\right)$ to account for the time lag, as described earlier and shown in (5). Turbocharger speed is calculated using (6), considering its angular acceleration in the previous time step $[11,12]$. "T $T_{b_{-} \text {turb }}$ " required for " $\mathrm{MFP}_{\text {trb }}$ " calculation, is predicted using (8) [13]. Considering pressure drop in the exhaust system as a quadratic restriction (see (9)), "pressure after turbine" $\left(p_{a_{\text {_trb }}}\right)$ is calculated using (10). Turbine map data is reversed to calculate "expansion ratio" $\left(\mathrm{ER}_{\mathrm{map}}\right)$ from " $\mathrm{MFP}_{\text {trb }}$ " and corrected turbine speed. This turbine map data is converted to a set of polynomial curve equations to predict turbine operating parameters [14]. With " $p_{a_{\text {_t }} b \text { " and "ER }}$ map", revised " $p_{b_{-} \text {trb }}$ " is calculated using (11). Then, calculations are repeated taking this revised " $p_{b_{-} \text {trb }}$ " as an input, till difference between initial and revised " $p_{b_{-} \text {trb }}$ " satisfies the convergence criteria:

$$
\begin{aligned}
\dot{m}_{\mathrm{exh}(i)} & =\dot{m}_{\mathrm{air}(i-1)}+\dot{m}_{\mathrm{fuel}(i)}, \\
N_{\mathrm{TC}(i)} & =N_{\mathrm{TC}(i-1)}+\frac{d \omega_{\mathrm{TC}(i-1)}}{d t} \Delta t \\
\frac{d \omega_{\mathrm{TC}}}{d t} & =\frac{\tau_{\mathrm{trb}}-\tau_{\mathrm{cmp}}}{G_{\mathrm{TC}}}, \\
T_{b_{-} \mathrm{trb}(i)} & =T_{\mathrm{im}(i)}+\frac{\dot{m}_{\mathrm{fuel}(i)} Q_{L} f_{\mathrm{exh}}}{c_{p, \operatorname{exh}} \dot{m}_{\mathrm{exh}(i)}} \\
\Delta p_{\mathrm{exh}} & =\frac{\dot{m}_{\mathrm{exh}}^{2} k_{\mathrm{es}} R_{\mathrm{exh}} T_{a_{-} \mathrm{trb}}}{p_{a_{-} \mathrm{trb}}} .
\end{aligned}
$$

Hence,

$$
\begin{aligned}
p_{a_{-} \mathrm{trb}}-p_{\mathrm{amb}} & =\frac{\dot{m}_{\mathrm{exh}}^{2} k_{\mathrm{es}} R_{\mathrm{exh}} T_{a_{-} \mathrm{trb}}}{p_{a_{-} \mathrm{trb}}}, \\
p_{b_{-} \mathrm{trb}} & =p_{a_{-} \mathrm{trb}} \mathrm{ER}_{\mathrm{map}} .
\end{aligned}
$$

Intake side calculations are initiated taking " $\dot{m}_{\text {air }}$ " from the previous time step. "Pressure before compressor" $\left(p_{b_{-} \mathrm{cmp}}\right)$ is calculated considering "pressure drop across air cleaner" $\left(\Delta p_{\mathrm{ac}}\right)$ as a quadratic restriction (see (12) and (13)). "Intake manifold pressure" $\left(p_{\text {im }}\right)$ is calculated using "corrected engine swept volume" $\left(V_{s_{-} \text {corr }}\right)$ with the relation shown in (14), assuming that intake manifold pressure is the same as incylinder pressure at IVC. Then, "pressure after compressor" $\left(p_{a_{-} \mathrm{cmp}}\right)$ is calculated from " $p_{\mathrm{im}}$ " by adding pressure drop in the after-cooler (see (16)). With " $p_{a_{-} \text {cmp }}$ " and " $p_{b_{-} \text {cmp }}$ ", "compressor pressure ratio by mass flow rate" $\left(\mathrm{CR}_{\mathrm{mf}}\right)$ is calculated using (17). From the set of compressor map equations, "compressor pressure ratio from map" $\left(\mathrm{CR}_{\text {map }}\right)$ is calculated for the corresponding corrected mass flow parameter and corrected compressor speed. Calculations are repeated by adjusting " $\dot{m}_{\text {air }}$ " till the difference between " $\mathrm{CR}_{\mathrm{mf}}$ " and " $\mathrm{CR}_{\text {map }}$ " satisfies the convergence criteria. "EGR mass flow rate" $\left(\dot{m}_{\text {egr }}\right)$ is determined using the expression for choked flow through a restriction [8], as shown in (18). The controlling "EGR valve opening area" $\left(A_{\text {egr }}\right)$ is taken as the lower area from " $A_{\text {egr1 }}$ " and " $A_{\text {egr } 2}$ " calculated by (19) and (20), respectively:

$$
\begin{aligned}
& p_{b_{-} \mathrm{cmp}}=p_{\mathrm{amb}}-\Delta p_{\mathrm{ac}}, \\
& \Delta p_{\mathrm{ac}}=\frac{\dot{m}_{\mathrm{air}}^{2} k_{\mathrm{ac}} R_{\mathrm{air}} T_{\mathrm{amb}}}{p_{\mathrm{amb}}}, \\
& p_{\mathrm{im}}=\frac{\dot{m}_{\mathrm{air}} R_{\mathrm{air}} T_{\mathrm{im}}}{V_{s_{-} \text {corr }}}, \\
& V_{s_{-} \text {corr }}=V_{s} \eta_{v}(1-r),
\end{aligned}
$$




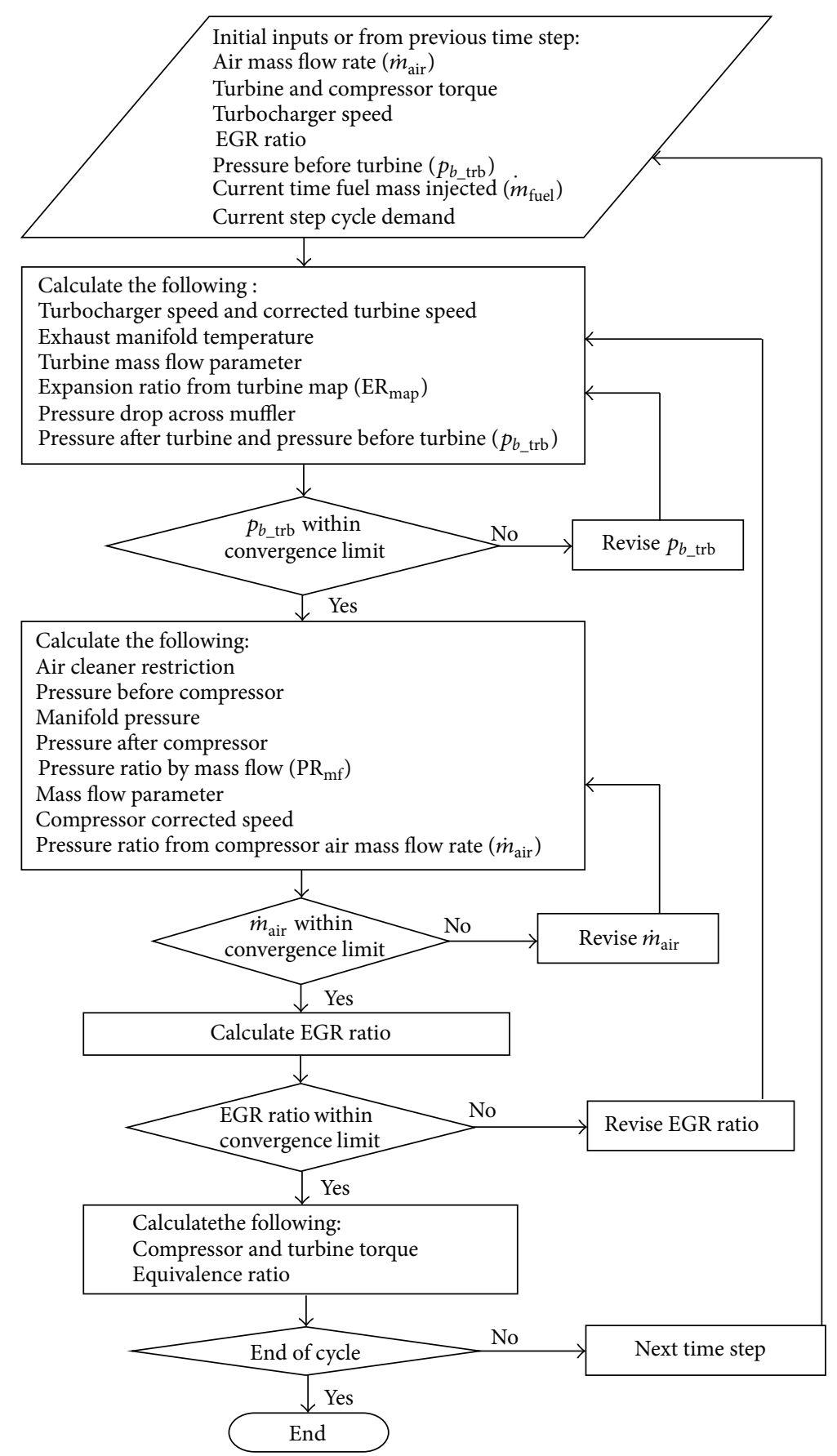

FIgURE 2: AHS model for transient cycle.

$$
\begin{aligned}
& p_{a_{-} \mathrm{cmp}}=p_{\mathrm{im}}+\Delta p_{\mathrm{int}}, \\
& \mathrm{PR}_{\mathrm{mf}}=\frac{p_{a_{-} \mathrm{cmp}}}{p_{b_{-} \mathrm{cmp}}}, \\
& \dot{m}_{\mathrm{egr}}=c_{d_{-} \text {egr }} A_{\text {egr }} \frac{p_{\mathrm{em}}}{\sqrt{T_{\mathrm{em}} R_{\mathrm{exh}}}} f\left(\frac{p_{\mathrm{im}}}{p_{\mathrm{em}}}, \gamma_{\mathrm{exh}}\right), \\
& A_{\text {egrl }}=\frac{\pi D_{\mathrm{egr}}^{2}}{4},
\end{aligned}
$$$$
\begin{aligned}
& A_{\mathrm{egr} 2}=\pi D_{\mathrm{egr}} h_{\mathrm{egr}}, \\
& \left(\frac{p_{\mathrm{im}}}{p_{\mathrm{em}}}, \gamma_{\mathrm{exh}}\right)
\end{aligned}
$$$$
=\sqrt{\frac{2 \gamma_{\mathrm{exh}}}{\gamma_{\mathrm{exh}}-1}\left(\left(\frac{p_{\mathrm{im}}}{p_{\mathrm{em}}}\right)^{2 / \gamma_{\mathrm{exh}}}-\left(\frac{p_{\mathrm{im}}}{p_{\mathrm{em}}}\right)^{\left(\gamma_{\mathrm{exh}}+1\right) / \gamma_{\mathrm{exh}}}\right)},
$$$$
\text { If } \frac{p_{\mathrm{im}}}{p_{\mathrm{em}}} \geq \xi
$$ 


$$
\begin{aligned}
& f\left(\frac{p_{\mathrm{im}}}{p_{\mathrm{em}}}, \gamma_{\mathrm{exh}}\right)=\sqrt{\gamma_{\mathrm{exh}}\left(\frac{2}{\gamma_{\mathrm{exh}}+1}\right)^{\gamma_{\mathrm{exh}+1} / \gamma_{\mathrm{exh}-1}}}, \\
& \text { If } \frac{p_{\mathrm{im}}}{p_{\mathrm{em}}}<\xi, \\
& \xi=\left(\frac{2}{\gamma_{\mathrm{exh}}+1}\right)^{\gamma_{\mathrm{exh}} / \gamma_{\mathrm{exh}-1}} .
\end{aligned}
$$

Based on the experimental investigations, values used for the model constants are " $f_{\text {exh }} "=0.3$, " $k_{\text {es }} "=1.2 \times 10^{6} \mathrm{~m}^{-4}$, and " $k_{\mathrm{ac}} "=6.7 \times 10^{5} \mathrm{~m}^{-4}$.

Compressor operating efficiency is determined from corrected mass flow parameter and corrected compressor speed, using the set of equations representing compressor efficiency map. Similarly, turbine operating efficiency is determined from expansion ratio and corrected turbine speed and from the set of turbine efficiency map equations. From this data compressor torque, turbine torque and turbocharger acceleration are calculated, to be used for the next time step.

2.1.3. Combustion Model. Combustion and emission parameters are calculated at the interval of $0.1^{\circ} \mathrm{CA}$ from IVC to $\mathrm{EVO}$, for the operating cycle at one-second time interval. Combustion model starts from prediction of compression pressure, considering a polytropic compression process from IVC to SOC. Hardenburg and Hase correlation as referred by Lakshminarayan and Aghav [15] as well as correlation proposed by Jung and Assanis [16] have been considered for prediction of the "polytropic index" $(n)$ of the compression process. After investigations with experimental results, it has been observed that predictions by Jung correlation (24) are closer to the measured data. However, it has also been observed that the predicted compression pressure matches the experimental data only at one speed. Hence, to improve the model prediction accuracy at other operating speeds, Jung correlation model is modified by introducing "engine speed" $(N)$ dependent correction, as shown in (25):

$$
\begin{aligned}
& n=1.338-6 \times 10^{-5} T_{\text {cyl }}+1 \times 10^{-8} T_{\text {cyl }}{ }^{2}, \\
& n=1.4-\frac{60}{N}-6 \times 10^{-5} T_{\text {cyl }}+1 \times 10^{-8} T_{\text {cyl }}^{2} .
\end{aligned}
$$

For prediction of "ignition delay" $\left(\tau_{\text {id }}\right)$, Arrhenius equation with model constants proposed by Wolfer as per Heywood [17] and with model constants suggested by Watson as per Arsie et al. [18] and correlation proposed by Hardenberg and Hase [19-21] have been considered. On further investigations with experimental data, Hardenberg and Hase correlation (26) is selected for model formulation. To account for change in cylinder pressure and temperature during the ignition delay period, time at which combustion starts is determined by integrating the reciprocals of instantaneous estimates of " $\tau_{\mathrm{id}}$ " [22], as given in (27):

$$
\begin{aligned}
& \tau_{\mathrm{id}}=\left(0.36+0.22 \bar{u}_{\mathrm{pist}}\right) \\
& \cdot \operatorname{Exp}\left[E_{A}\left(\frac{1}{\widetilde{R} T_{\mathrm{cyl}}}-\frac{1}{17190}\right)\left(\frac{21.2}{p_{\mathrm{cyl}}-12.4}\right)^{0.63}\right], \\
& \int_{t_{\mathrm{SOI}}}^{t_{\mathrm{SOC}}}\left(\frac{1}{\tau_{\mathrm{id}}}\right)=1 .
\end{aligned}
$$

For gross heat release $\left(Q_{g}\right)$ predictions, Watson model $[9,17,23]$ as well as Mixing Controlled Combustion (MCC) model [24] has been considered. In the investigations, it has been observed that prediction by Watson model is closer to the experimental data. However, it has been also observed that the model predicts cylinder pressure with good accuracies only in narrow band of operating loads and it needs modifications to improve prediction accuracies at other loads. In the Watson model, fuel burn rate is estimated by (28), which is a weighted addition of premixed and diffusion combustion. As shown in (29), the "combustion weight factor" $(\beta)$ varies only with "equivalence ratio" $(\varphi)$ and " $\tau_{\mathrm{id}}$ "; however there is no consideration for change in "duration of injection" $\left(D_{\text {inj }}\right)$, which varies significantly from full load to low load. Hence the model constant " $b$ " is converted to a variable dependent on " $D_{\text {inj }}$ " as shown in (30). This is based on the detailed investigations done and explained by the authors in [25]:

$$
\begin{aligned}
\frac{m_{f, b\left(t^{\prime}\right)}}{m_{f, o}} & =\beta f_{1}+(1-\beta) f_{2}, \\
\beta & =1-\frac{a \phi^{b}}{\tau_{\mathrm{id}}^{c}}, \\
b & =0.95-0.07 D_{\mathrm{inj}} .
\end{aligned}
$$

Watson model constants " $a$ " and " $c$ " in (29) are taken as 0.54 and 0.5 , respectively. For prediction of heat loss, correlation proposed by Annand (see (31)) $[9,26]$ is considered for model formulation, as it considers radiation heat loss in addition to the convective heat loss:

$$
\begin{aligned}
& \frac{d Q_{\mathrm{ht}}}{d \theta} \\
& \quad=A_{\text {pist }}\left[a_{1} \frac{k_{g}}{D_{\text {pist }}} \operatorname{Re}^{b_{1}}\left(T_{\text {cyl }}-T_{w}\right)+c_{1}\left(T_{\text {cyl }}^{4}-T_{w}^{4}\right)\right] \\
& \quad\left(\frac{1}{6 N}\right) .
\end{aligned}
$$

Annand model parameters in (31), " $a_{1}$, " " $b_{1}$," and " $c_{1}$," are taken as $0.5,0.65$, and $3 \sigma$, respectively [9]. It is a wellknown fact that update of cylinder wall temperature is notably delayed compared with changes in fuelling. This led many researchers to assume constant wall temperature throughout the transient event. In the study of a number of simplifications on a medium duty engine, it was shown 
that assumption of constant wall temperature is justified [9]. Claes Ericson et al. [8] have also used fixed value of wall temperature while modelling diesel engine combustion and NOx formation. With the same simplified approach, "cylinder wall temperature" $\left(T_{w}\right)$ is taken as $523 \mathrm{~K}$, constant throughout the transient cycle.

2.1.4. Two-Zone and Emissions Models. Single-zone models are simple for calculations; however they cannot predict spatial temperature differences [27]. Hence, two-zone model has been used to calculate burned and unburned zone temperatures. Adiabatic flame temperature is calculated by enthalpy balance assuming perfectly burned gas mixture and flame temperatures are calculated considering radiation loss [13]. Thermal NO is predicted at burned zone temperatures using basic Zeldovich mechanism, which considers two reactions as given in (32) and (33) [28]. As 0D model emission outputs are required to be corrected to get the prediction values, the "model output $\mathrm{NOx}$ " $\left(\mathrm{NOx}_{\text {model }}\right)$ is corrected by (34) to get "engine-out NOx prediction" $\left(\mathrm{NOx}_{\text {predicted }}\right)$ :

$$
\begin{gathered}
\mathrm{O}+\mathrm{N}_{2} \stackrel{\mathrm{K}_{1}}{\longleftrightarrow} \mathrm{NO}+\mathrm{N} \\
\mathrm{N}+\mathrm{O}_{2} \stackrel{\mathrm{K}_{2}}{\longleftrightarrow} \mathrm{NO}+\mathrm{O} \\
\mathrm{NOx}_{\text {predicted }}=\mathrm{NOx}_{\text {model }}+C_{\mathrm{NOx}}
\end{gathered}
$$

where $C_{\mathrm{NOx}}$ used is $4.5 \times 10^{-6} \mathrm{~kg} / \mathrm{s}$.

Hiroyasu model is considered for soot modelling, upon investigations of selected soot prediction models $[9,16,18$, 29]. Hiroyasu soot model consists of two Arrhenius equations for soot formation and oxidation rates as shown in (35) and (36), respectively. The difference between soot formation and oxidation rates gives net soot (see (37)). It has been observed that the selected model predicts soot with good accuracy only in a very narrow speed-load range. Hence, to improve prediction accuracy throughout the operating speed-load range, model constant for soot formation " $A_{f}$ " is modified as a function of speed [18]. " $A_{f}$ " is calculated by (38), based on analysis of experimental data. The soot model output $\left(\right.$ Soot $\left._{\text {model }}\right)$ is corrected by (39) to get "engine-out soot prediction" (Soot predicted $)$ :

$$
\begin{aligned}
\frac{d m_{\mathrm{sf}}}{d t} & =A_{f} m_{\mathrm{fuel}} p_{\mathrm{cyl}}^{0.5} \exp \left(\frac{-E_{f}}{\mathrm{RT}_{\mathrm{cyl}}}\right), \\
\frac{d m_{\mathrm{so}}}{d t} & =A_{o} m_{\mathrm{sn}} Y o_{2} p_{\mathrm{cyl}}{ }^{1.8} \exp \left(\frac{-E_{o}}{\mathrm{RT}_{\mathrm{cyl}}}\right), \\
\frac{d m_{\mathrm{sn}}}{d t} & =\frac{d m_{\mathrm{sf}}}{d t}-\frac{d m_{\mathrm{so}}}{d t}, \\
A_{f} & =18.8 e^{1.94 \times 10^{-4} \mathrm{~N}}, \\
\text { Soot }_{\text {predicted }} & =m_{\text {soot }} \cdot \mathrm{Soot}_{\text {model }}+C_{\text {soot }} .
\end{aligned}
$$

Activation energies $E_{f}$ and $E_{o}$ are taken as $82000 \mathrm{~J} / \mathrm{mol}$ and $120000 \mathrm{~J} / \mathrm{mol}$, respectively [30]. " $A_{o}$ ", " $m_{\text {soot }}$ ", and " $C_{\text {soot }}$ " are taken as $1000,2.8$, and $4.0 \times 10^{-8} \mathrm{~kg} / \mathrm{s}$, respectively.

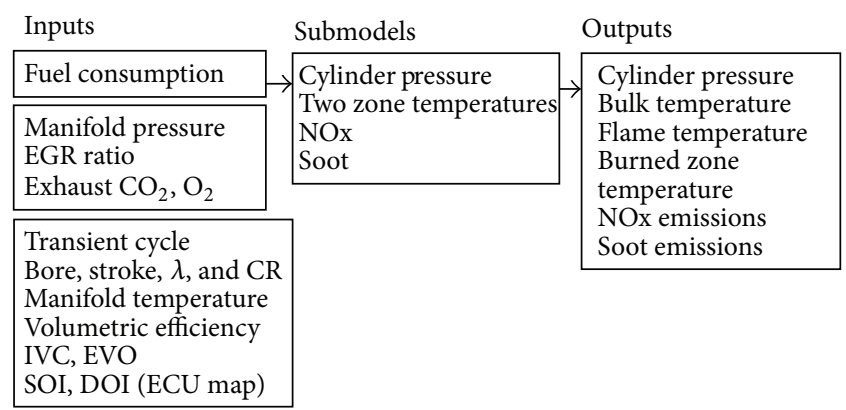

Figure 3: Combustion, two-zone, and emission models input, submodels, and output details.

$\mathrm{CO}_{2}$ concentration is calculated using equation for complete combustion since small concentration of species generated due to incomplete combustion does not have significant effect on $\mathrm{CO}_{2}$ concentration. Equation (40) considers the number of moles of the hydrocarbon fuel $(n)$, relative airfuel ratio $(\lambda)$, and EGR ratio $(r)$, while calculating elemental balance between reactants and products [17]. $\mathrm{CO}_{2}$ mole fraction is calculated by taking ratio of number of $\mathrm{CO}_{2}$ moles to the total number of moles of all combustion products:

$$
\begin{aligned}
& n \mathrm{C}_{a} \mathrm{H}_{b}+n \lambda\left(a+\frac{b}{4}\right)\left(\mathrm{O}_{2}+3.773 \mathrm{~N}_{2}\right) \\
& +n r\left(\frac{a}{(1-r)} \mathrm{CO}_{2}+\frac{b}{2(1-r)} \mathrm{H}_{2} \mathrm{O}\right. \\
& \left.+\frac{3.773 \lambda}{(1-r)}\left(a+\frac{b}{4}\right) \mathrm{N}_{2}+\frac{(\lambda-1)}{(1-r)}\left(a+\frac{b}{4}\right) \mathrm{O}_{2}\right) \\
& =\frac{n a}{(1-r)} \mathrm{CO}_{2}+\frac{n b}{2(1-r)} \mathrm{H}_{2} \mathrm{O}+\frac{3.773 n \lambda}{(1-r)}(a \\
& \left.+\frac{b}{4}\right) \mathrm{N}_{2}+\frac{n(\lambda-1)}{(1-r)}\left(a+\frac{b}{4}\right) \mathrm{O}_{2} .
\end{aligned}
$$

Input data, submodels used, and outputs of the combustion and emissions models are shown in Figure 3. Other details of emissions prediction models are explained by the authors in [31]. Experimental values of intake manifold temperatures $\left(T_{\mathrm{im}}\right)$ are taken as input to the model since these temperatures are highly dependent on intercooler and EGR cooler packaging. Input data of "SOI" and " $D_{\text {inj" }}$ " are calculated by interpolation of ECU map for "SOI" and "Energizing Time" (ET), respectively. "SOI" values taken from ECU map are corrected by adding $0.35 \mathrm{~ms}$ to account for lag between "ET" and "SOI" [32]. EGR valve lift data is taken from EGR valve lift ECU map.

2.2. Experimental Setup. Specifications of the engine selected for model validation are shown in Table 1. The selected high power density, high fuel injection pressure engine represents the modern and futuristic engines for agriculture and construction equipment applications. The test cell equipment, instrumentation, and the data acquisition system used for measurements are listed in Table 2. Engine dynamometer, 
TABLE 1: Specifications of the experimentation engine.

\begin{tabular}{lc}
\hline Engine type & DI diesel engine \\
\hline Aspiration & Turbocharged after-cooled \\
Bore $\times$ stroke & $95 \times 110 \mathrm{~mm}$ \\
Compression ratio & 18.0 \\
Fuel injection system & Common rail \\
EGR & High pressure \\
Application & Off-road \\
\hline
\end{tabular}

TABLE 2: Test cell instrumentation.

\begin{tabular}{lc}
\hline Instrument & Details \\
\hline Dynamometer & AVL APA 120 dynamometer \\
Air flow meter & Sensyflow hot-film mass flow meter \\
Fuel consumption meter & FEV Coriolis fuel mass flow meter \\
High-speed data acquisition & AVL IndiCom \\
Cylinder pressure sensor & AVL GH12D Piezoelectric \\
NOx measurement & AVL i60 emission system \\
Smoke measurement & AVL 439 Opacimeter \\
\hline
\end{tabular}

measuring equipment, instrumentation, and data acquisition are suitable to run and acquire experimental data under a transient operating cycle.

\section{Model Validation and Discussions}

3.1. Combustion Model Response. For emissions prediction on transient cycle, the emission model should have capability to predict correct emission trends over load and start of injection (SOI) changes. Hence, before validation of the comprehensive model on NRTC, combustion and emissions models are checked for their responses to load and SOI changes.

Full loads, $75 \%$ and $50 \%$ loads at maximum power speed $(2000 \mathrm{rpm})$ and maximum torque speed (1300 rpm), are selected for the load response check. Figure 4 shows comparisons of predicted and measured cylinder pressures at these selected speed-load points. It can be seen that, at all the points, compression pressures and SOC are predicted with good accuracies. Predicted combustion pressure and pressure during expansion stroke are also closely matching with the measured curves for all the speed-load points. This shows that formulated model, with modifications, can predict cylinder pressure in the complete speed-load range.

Comparisons of predicted and measured engine-out NOx trends over the selected load changes are shown in Figure 5. The formulated model is able to predict the NOx emissions trends at both speeds. Relative errors (RE) of NOx prediction with respect to the measured NOx values are within $-17.1 \%$ to $18 \%$, which is considered as a good NOx emissions prediction.

Similarly, comparison of predicted and measured soot trends is also shown in Figure 5. Soot model is also able to predict the soot emission trends at both speeds. RE of predicted soot from the measured values are from $-22.5 \%$ to $46.3 \%$. At full loads the relative errors are in the range of $20 \%$ and at part loads they are more than $20 \%$; however deviations in the absolute values are not significant since soot values are very low at part loads.

To assess model response to change in SOI, NOx and soot emissions are predicted with change in SOI from $10^{\circ} \mathrm{bTDC}$ to $6^{\circ} \mathrm{bTDC}$. Figure 6 shows that predicted mass emissions trends are fairly matching with the measured results. RE of predicted NOx from the measured values are from 10.3\% to $18.03 \%$, whereas RE of predicted soot from the measured values are from $-18.1 \%$ to $15.9 \%$. This shows that formulated model is capable of predicting NOx and soot emissions with changes in SOI.

3.2. Predictions on the Transient Cycle. NRTC is considered as one of the most stringent transient cycles, since it has higher speed-load variations compared to the other legislative transient cycles as can be seen from the denormalised NRTC for the experimentation engine (Figure 7). This formulated model has been built in $\mathrm{C}++$. The average simulation run time for the entire NRTC is $610 \mathrm{~s}$. Comparison of model predicted results with measured values, on the experimental engine, is shown for the first $800 \mathrm{~s}$ of the denormalised NRTC.

3.2.1. Transient Fuel Consumption. Figure 8 shows comparison of predicted "fuel mass injected" with the same output acquired from engine ECU. It can be seen that transient fuel consumption predicted by the model is closely matching with the ECU output. From this comparison, it can be concluded that the formulated fuel mass flow model predicts fuel consumption under transient operations, with very good accuracy.

Though the fuel consumption model is validated on NRTC, it is expected that this model would be able to predict fuel consumption over any transient cycle for this category of off-road engines as well as for on-road commercial engines, without much change in model constants. It is also expected that prediction of transient fuel consumption with change in type of fuel can be done by tuning value of the "fuel mass model constant" $\left(C_{\mathrm{IP}}\right)$ in (1).

3.2.2. Transient Air Handling Parameters. Comparison of model predicted and measured air mass flow rate over the transient cycle is shown in Figure 9. It can be seen that model predicted air mass flow rate curve is in agreement with the curve of measured data. This shows that formulated AHS model is able to capture responses of all related subsystems in air handling. Figure 10 shows comparisons of intake side pressures with the measured data. Curve of model predicted pressure after compressor (gauge) is in agreement with the measured data and it can be concluded that the prediction model is able to properly capture the compressor characteristics. Intake depression curves of the predicted and measured values are in agreement. This shows that response of air cleaner pressure drop is properly captured by the model.

Comparisons of predicted and measured exhaust side pressures are shown in Figure 11. Predicted pressure before turbine (gauge) and exhaust back pressure curves of the predicted results are closely matching with the measured data curves. Hence, it can be concluded that turbine characteristics 

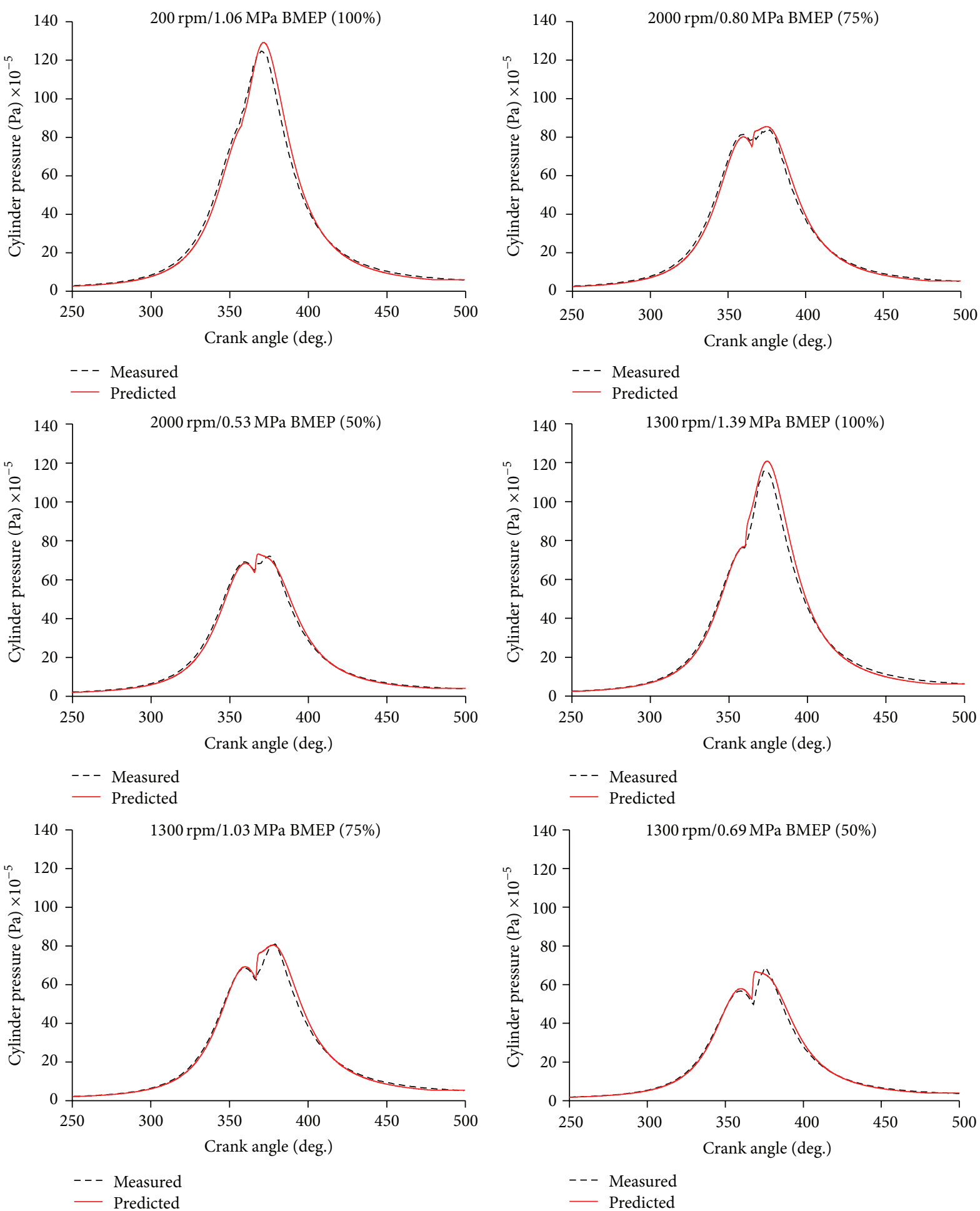

FIGURE 4: Comparisons of predicted and measured cylinder pressures at maximum power and maximum torque speeds.

and exhaust system pressure drop are properly captured by the prediction model.

Figure 12 shows comparison of model predicted and measured EGR ratios. Though trends of predicted and measured values are matching, amplitudes of peaks and valleys are more in case of predicted EGR ratio curve compared to experimental curve. This could be due to averaging of instantaneous EGR mass flow rates in case of experimental results, due to volumes in the EGR pipes.

In this model, value of the "air cleaner restriction constant" $\left(k_{\mathrm{ac}}\right)$ is selected for dry type air cleaner which is commonly used on these category engines. Also, value of 

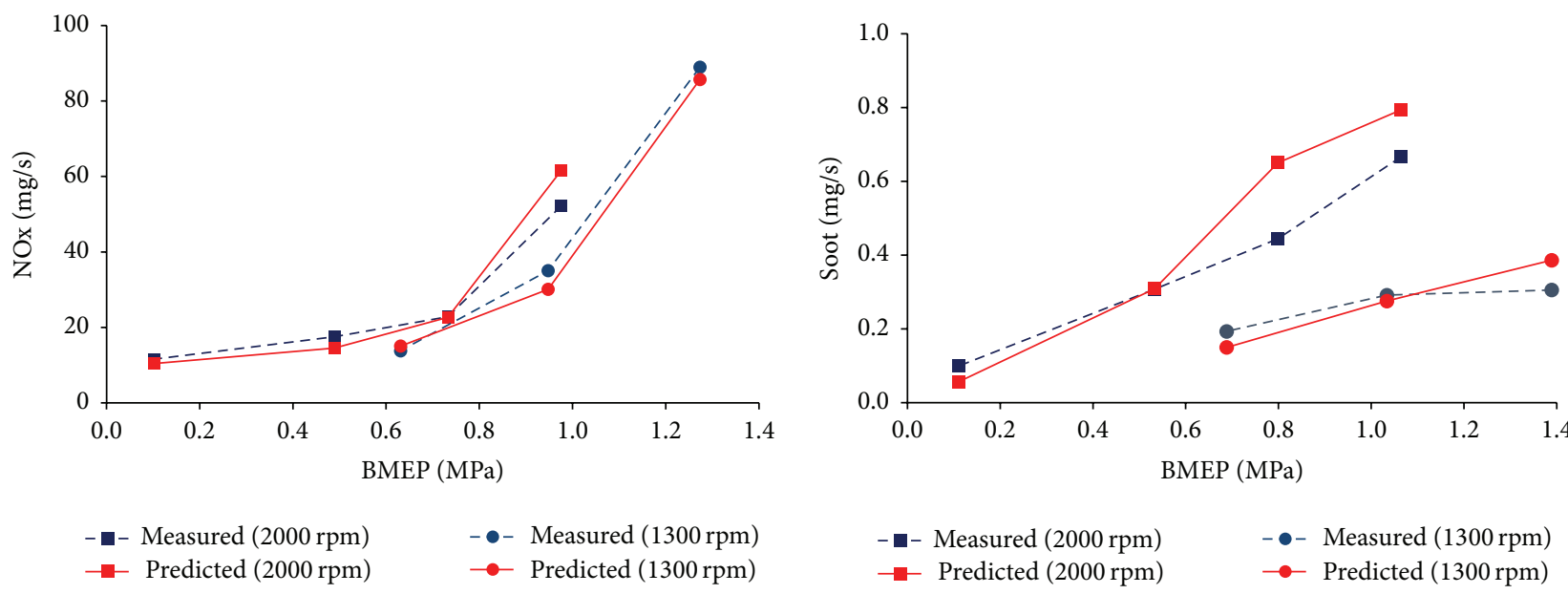

FIGURE 5: Comparisons of predicted NOx and soot trends with measured results at maximum power and maximum torque speeds.

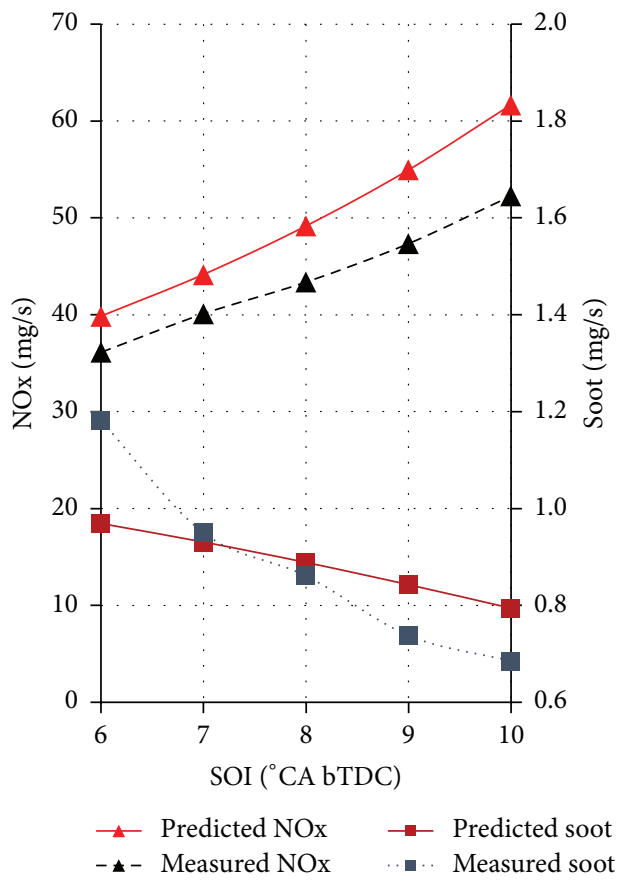

FIGURE 6: Comparisons of predicted NOx and soot mass emissions with measured results over SOI variations.

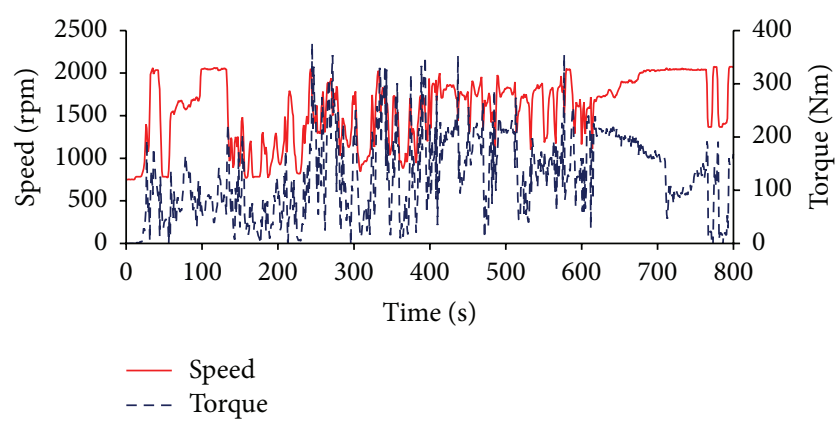

FIGURE 7: Denormalised NRTC for the experimentation engine (initial $800 \mathrm{~s}$ ).

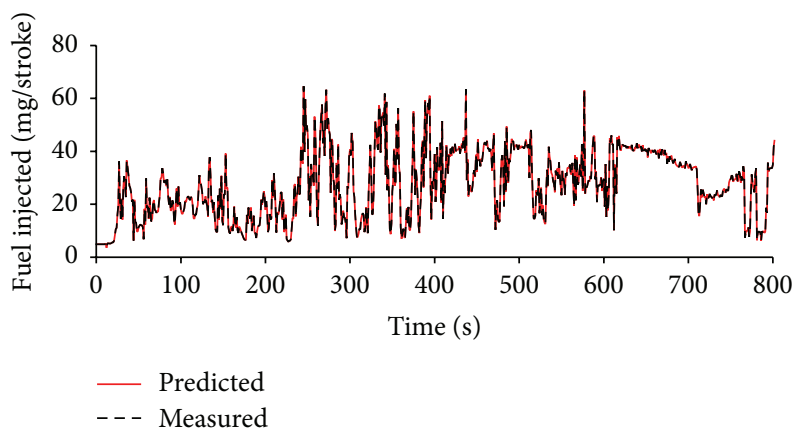

FIgURE 8: Comparison of predicted and ECU output of fuel mass injected.

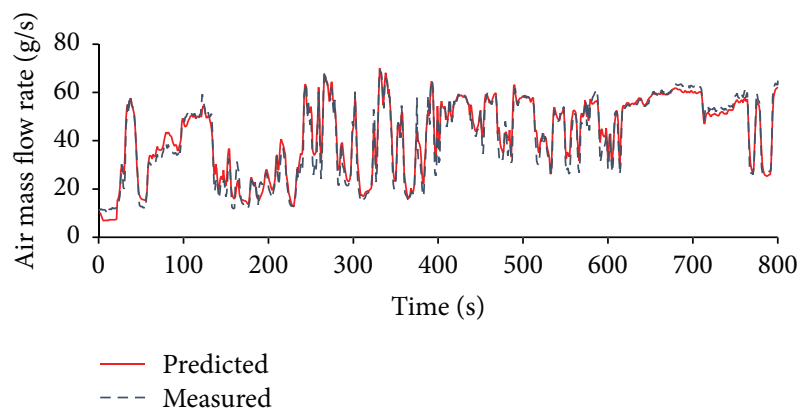

FIGURE 9: Comparison of predicted and measured air mass flow rates.

"exhaust system restriction constant" $\left(k_{\mathrm{es}}\right)$ is selected for exhaust system with silencer and DOC. Change in the " $k_{\mathrm{es}}$ " value (see (9)) will be required, if there is addition of exhaust after-treatment devices. With this change, it is expected that the formulated model would be able to predict AHS parameters over any transient cycle, for this category of engines as well as for on-road commercial engines. It is expected that, with change in " $f_{\text {exh }}$ " value (see (8)), the model would be able to predict AHS parameters with different fuels. 


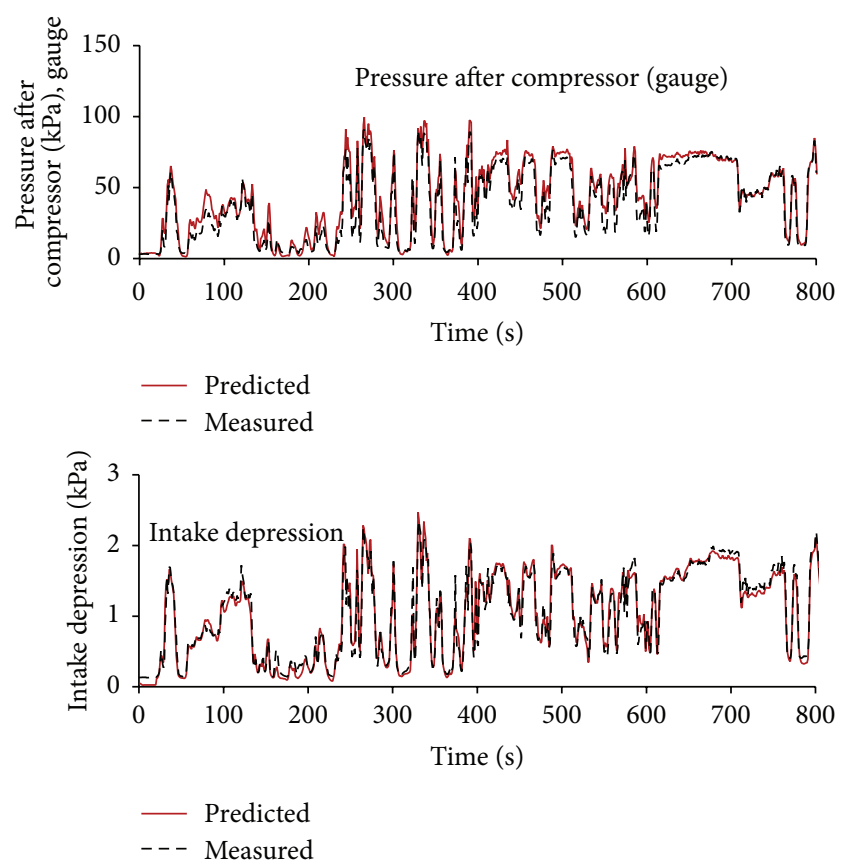

FIGURE 10: Comparisons of intake side predicted and measured pressures.
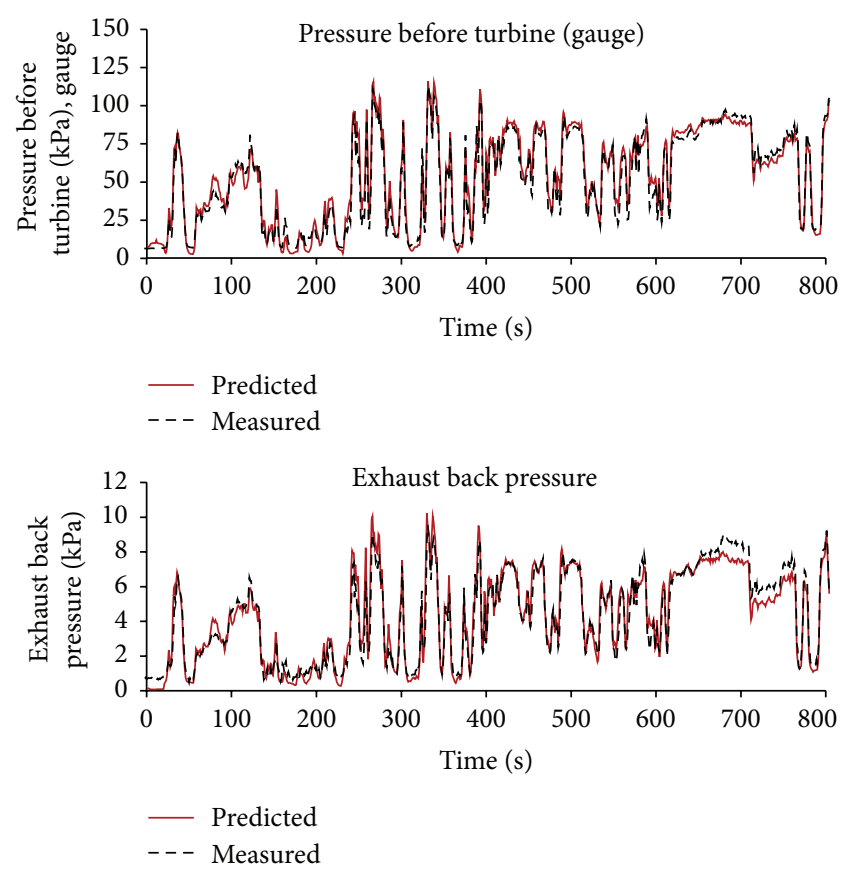

Figure 11: Comparisons of exhaust side predicted and measured pressures.

3.2.3. NOx and Soot Emissions. Figure 13 shows comparison of predicted NOx with measurement results. Trend of the predicted NOx emissions is matching with the measurements; however there are differences in the amplitudes of NOx peaks, which could be due to peaks in the predicted EGR ratios taken

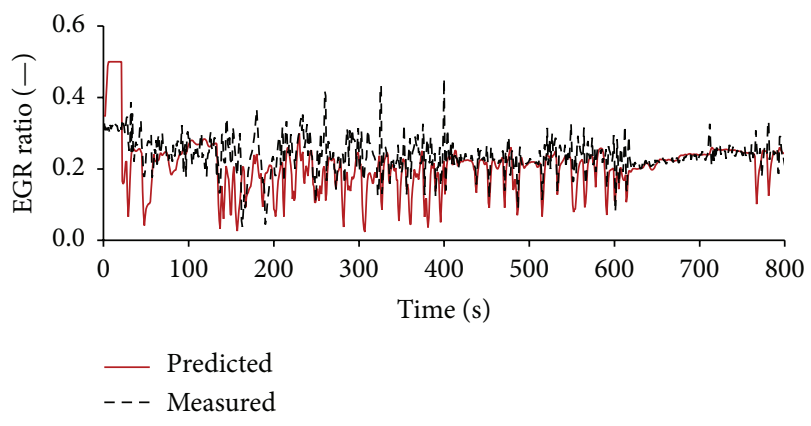

FIGURE 12: Comparisons of predicted and measured EGR ratios.

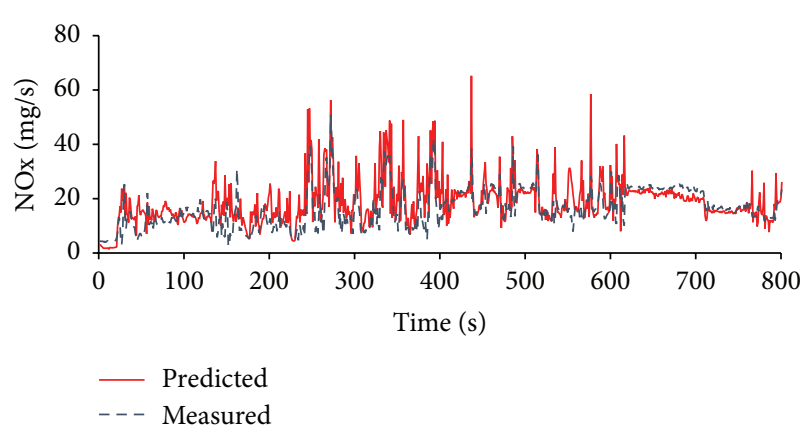

FIGURE 13: Comparison of measured and predicted NOx.

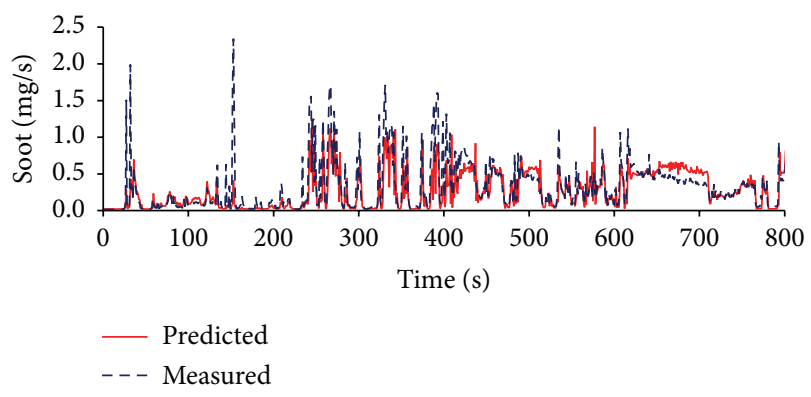

FIGURE 14: Comparison of measured and predicted soot.

as inputs to this prediction. To assess model prediction accuracy, accumulated NOx mass emissions over the entire NRTC (1200 s) have been evaluated. Model predicted accumulated NOx is $2.21 \times 10^{-2} \mathrm{~kg}$ as against measured accumulated NOx of $1.91 \times 10^{-2} \mathrm{~kg}$. The relative error $(\mathrm{RE})$ of the predicted NOx with respect to the measured result is $15.8 \%$. From emission trends and the RE in accumulated values, it can be concluded that the formulated model can predict transient NOx emissions with acceptable accuracy.

Figure 14 shows comparison of measured and predicted soot emissions. Soot emissions trend predicted by the model is matching with the experimental values except at very high soot peaks. Accumulated model predicted soot over the entire NRTC $(1200 \mathrm{~s})$ is $2.80 \times 10^{-4} \mathrm{~kg}$, as against accumulated measured soot of $3.31 \times 10^{-4} \mathrm{~kg}$. The relative error of the predicted soot with respect to the measurement is $-15.4 \%$. 


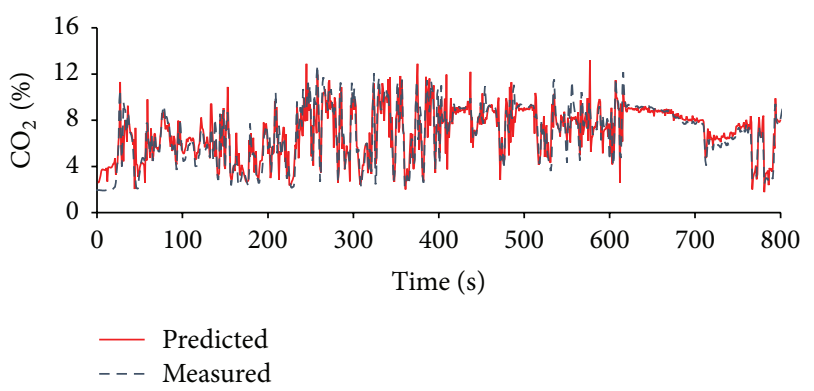

FIGURE 15: Comparison of measured and predicted $\mathrm{CO}_{2}$ concentration.

Hence, it can also be concluded that the formulated model predicts transient soot emissions with reasonable accuracy.

Figure 15 shows comparison of predicted and measured $\mathrm{CO}_{2}$ concentration. It can be seen that the predicted transient $\mathrm{CO}_{2}$ concentration values are closely matching with measured transient $\mathrm{CO}_{2}$ concentrations. Predicted $\mathrm{CO}_{2}$ curve is closely matching with the curve of measured values.

The above results show that the comprehensive model has potential to predict NOx and soot emissions on transient cycle. The formulated transient emission model is validated on NRTC; however it is expected that, with minor tuning in emission correction parameters in (34) and (39), the formulated model would be able to predict emissions over any transient cycle for this category of engines as well as for on-road commercial engines. Additionally minor tuning of parameters in (30) would be required for NOx and soot predictions with different fuels.

\section{Summary and Conclusions}

A comprehensive zero-dimensional predictive model has been formulated for soot and NOx emissions prediction under transient operating cycle. Responses of combustion and emissions models have been validated for load and SOI changes and prediction results of the comprehensive model have been validated using a turbocharged common rail engine on NRTC. The formulated model has predicted transient fuel consumption, air handling system parameters, and soot and NOx emissions with good accuracies.

It can be concluded that $0 \mathrm{D}$ models can be used for prediction of transient emissions on modern engines, to reduce time and cost of experimentations. Though the model has been validated on a diesel engine for NRTC, it can be extended for other applications and fuels. With modifications in submodels, more prediction parameters can be added to the model to make it an effective design tool.

\section{Nomenclature}

$A_{\text {pist }}:$ Area of piston, $\mathrm{m}^{2}$

$C_{d_{\text {_egr }}}:$ EGR valve discharge coefficient

$C_{p \text { exh }}$ : Exhaust gas specific heat, $\mathrm{J} \mathrm{kg}^{-1} \mathrm{~K}^{-1}$

$D_{\text {egr }}$ : EGR valve diameter, $\mathrm{m}$

$D_{\text {pist }}$ : Piston diameter, $\mathrm{m}$

\begin{tabular}{|c|c|}
\hline$f_{1}:$ & Premixed burning fraction \\
\hline$f_{2}:$ & Diffusion burning fraction \\
\hline$G_{E}:$ & Engine mass moment of inertia, $\mathrm{kg} \mathrm{m}^{2}$ \\
\hline$G_{\mathrm{TC}}:$ & $\begin{array}{l}\text { Turbocharger mass moment of inertia, } \\
\mathrm{kg} \mathrm{m}^{2}\end{array}$ \\
\hline$h_{\text {egr }}:$ & EGR valve lift, $\mathrm{m}$ \\
\hline$k_{g}:$ & Gas thermal conductivity, $\mathrm{W} \mathrm{m}^{-1} \mathrm{~K}^{-1}$ \\
\hline$\dot{m}:$ & Mass flow rate, $\mathrm{kg} \mathrm{s}^{-1}$ \\
\hline$m_{f, b}:$ & Cumulative fuel burned, $\mathrm{kg}$ \\
\hline$m_{f, o}:$ & Fuel injected per cycle, kg \\
\hline$m_{\mathrm{sf}}, m_{\mathrm{sn}}, m_{\mathrm{so}}:$ & Mass of soot, $\mathrm{kg}$ \\
\hline$N_{\mathrm{TC}}:$ & Turbocharger speed, $\mathrm{s}^{-1}$ \\
\hline$n_{\text {cyl }}:$ & Number of cylinders \\
\hline$p_{\mathrm{amb}}:$ & Ambient pressure, $\mathrm{Pa}$ \\
\hline$p_{\text {cyl }}:$ & Cylinder pressure, $\mathrm{Pa}$ \\
\hline$Q_{\mathrm{ht}}:$ & Heat loss, J \\
\hline$Q_{g}:$ & Gross heat release, J \\
\hline$Q_{L}:$ & Fuel lower calorific value, $\mathrm{J} \mathrm{kg}^{-1}$ \\
\hline$r:$ & Engine crank radius (m), EGR ratio $(-)$ \\
\hline$T_{\mathrm{amb}}:$ & Ambient temperature, $\mathrm{K}$ \\
\hline$T_{\text {cyl }}:$ & Cylinder gas bulk temperature, $\mathrm{K}$ \\
\hline${ }^{\circ} \mathrm{CA}:$ & Degree crank angle \\
\hline$\alpha, \beta_{1 m}, \beta_{f}, \gamma:$ & FMEP model constants \\
\hline$\sigma:$ & $\begin{array}{l}\text { Stefan-Boltzmann constant, } 5.67 \times \\
10^{-8} \mathrm{Wm}^{-2} \mathrm{~K}^{-4}\end{array}$ \\
\hline $\bar{u}_{\text {pist }}:$ & Mean piston speed, $\mathrm{m} \mathrm{s}^{-1}$ \\
\hline$\tau:$ & Torque, $\mathrm{Nm}$ \\
\hline$\tau_{\mathrm{cmp}}:$ & Compressor torque, $\mathrm{Nm}$ \\
\hline$\tau_{\text {trb }}:$ & Turbine torque, $\mathrm{Nm}$ \\
\hline$\Delta:$ & Difference \\
\hline$\omega:$ & Engine angular speed, $\mathrm{rad} \mathrm{s}^{-1}$ \\
\hline$\omega_{\mathrm{TC}}:$ & Turbocharger angular speed, $\mathrm{rad} \mathrm{s}^{-1}$ \\
\hline$\lambda:$ & Relative air-fuel ratio \\
\hline bTDC: & Before top dead centre \\
\hline DOC: & Diesel oxidation catalyst \\
\hline ECU: & Electronic control unit \\
\hline EGR: & Exhaust gas recirculation \\
\hline EVO: & Exhaust valve opening, ${ }^{\circ} \mathrm{CA}$ \\
\hline IVC: & Intake valve closure, ${ }^{\circ} \mathrm{CA}$ \\
\hline MCC: & Mixing Controlled Combustion \\
\hline $\mathrm{NOx}_{\text {model }}:$ & NOx predicted by model, $\mathrm{kg} \mathrm{s}^{-1}$ \\
\hline NOx predicted: & Predicted engine-out NOx, $\mathrm{kg} \mathrm{s}^{-1}$ \\
\hline SOC: & Start of combustion, ${ }^{\circ} \mathrm{CA}$ \\
\hline Soot ${ }_{\text {model }}:$ & Soot predicted by model, $\mathrm{kg} \mathrm{s}^{-1}$ \\
\hline Soot $t_{\text {predicted: }}$ & Predicted engine-out soot, $\mathrm{kg} \mathrm{s}^{-1}$. \\
\hline
\end{tabular}

\section{Competing Interests}

The authors declare that they have no competing interests.

\section{Acknowledgments}

The authors thank the laboratory staff of Powertrain Engineering Department, The Automotive Research Association 
of India, for their help in this work. The authors also thank the Director of ARAI for her valuable support.

\section{References}

[1] C. D. Rakopoulos, A. M. Dimaratos, E. G. Giakoumis, and D. C. Rakopoulos, "Exhaust emissions estimation during transient turbocharged diesel engine operation using a two-zone combustion model," International Journal of Vehicle Design, vol. 49, no. 1-3, pp. 125-149, 2009.

[2] C. Ericson, B. Westerberg, and R. Egnell, "Transient emission predictions with quasi stationary models," SAE Technical Paper 2005-01-3852, 2005.

[3] C. D. Rakopoulos and E. G. Giakoumis, "Review of thermodynamic diesel engine simulations under transient operating conditions," SAE Paper 2006-01-0884, SAE International, 2006.

[4] K. Nikzadfar and A. H. Shamekhi, "An extended mean value model (EMVM) for control-oriented modeling of diesel engines transient performance and emissions," Fuel, vol. 154, pp. 275292, 2015.

[5] K. Ebrahimi, M. Bazargan, and S. A. Jazayeri, "A new phenomenological model for combustion and performance studies of direct injection diesel engines," SAE Paper 2007-01-1904, SAE International, 2007.

[6] J. R. Serrano, F. J. Arnau, V. Dolz, and P. Piqueras, "Methodology for characterisation and simulation of turbocharged diesel engines combustion during transient operation. Part 1: data acquisition and post-processing," Applied Thermal Engineering, vol. 29, no. 1, pp. 142-149, 2009.

[7] J. R. Serrano, H. Climent, C. Guardiola, and P. Piqueras, "Methodology for characterisation and simulation of turbocharged diesel engines combustion during transient operation, part 2: phenomenological combustion simulation," Applied Thermal Engineering, vol. 29, no. 1, pp. 150-158, 2009.

[8] C. Ericson, B. Westerberg, M. Andersson, and R. Egnell, "Modelling diesel engine combustion and $\mathrm{NO}_{x}$ formation for model based control and simulation of engine and exhaust aftertreatment systems," SAE Technical Paper 2006-01-0687, 2006.

[9] C. D. Rakopoulos and E. G. Giakoumis, Diesel Engine Transient Operation, Springer, London, UK, 2009.

[10] N. Watson and M. S. Janota, Turbocharging the Internal Combustion Engine, Macmillan Publishers, London, UK, 1982.

[11] C. Rakopoulos, E. Giakoumis, D. Hountalas, and D. Rakopoulos, "The effect of various dynamic, thermodynamic and design parameters on the performance of a turbocharged diesel engine operating under transient load conditions," SAE Technical Paper 2004-01-0926, 2004.

[12] M. Jung, R. G. Ford, K. Glover, N. Collings, U. Christen, and M. J. Watts, "Parameterization and transient validation of a variable geometry turbocharger for mean-value modelling at low and medium speed-load points," SAE Paper 2002-01-2729, SAE International, 2002.

[13] C. Ericson, $\mathrm{NO}_{x}$ modelling of a complete diesel engine/SCR system [Licentiate thesis], Lund University, Lund, Sweden, 2007.

[14] A. Gambarotta, G. Lucchetti, and I. Vaja, "Real-time modelling of transient operation of turbocharged diesel engines," Proceedings of the Institution of Mechanical Engineers Part D: Journal of Automobile Engineering, vol. 225, no. 9, pp. 1186-1203, 2011.
[15] P. A. Lakshminarayanan and Y. V. Aghav, Modelling Diesel Combustion, Springer, Amsterdam, The Netherlands, 2010.

[16] D. Jung and D. N. Assanis, "Multi-zone DI diesel spray combustion model for cycle simulation studies of engine performance and emissions," SAE Paper 2001-011246, SAE International, 2001.

[17] J. B. Heywood, Internal Combustion Engine Fundamentals, McGraw-Hill, 1988.

[18] I. Arsie, F. Di Genova, C. Pianese et al., "Development and identification of phenomenological models for combustion and emissions of common-rail multi-jet diesel engines," SAE Paper 2004-01-1877, SAE International, 2004.

[19] H. Hardenberg and F. Hase, "An empirical formula for computing the pressure rise delay of a fuel from its cetane number and from the relevant parameters of direct-injection diesel engines," SAE Technical Paper 790493, 1979.

[20] P. Kirchen and K. Boulouchos, "Development and validation of a phenomenological mean value soot model for common-rail diesel engines," SAE Technical Paper 2009-01-1277, 2009.

[21] C. V. N. Abbe, R. Nzengwa, R. Danwe, Z. M. Ayissi, and M. Obonou, "A study on the 0D phenomenological model for diesel engine simulation: application to combustion of neem methyl esther biodiesel," Energy Conversion and Management, vol. 89, pp. 568-576, 2015.

[22] G. Stiesch and G. Merker, "A phenomenological model for accurate and time efficient prediction of heat release and exhaust emissions in direct-injection diesel engines," SAE Technical Paper 1999-01-1535, 1999.

[23] P. Casolia, A. Gambarotta, N. Pompini, U. Caiazzo, E. Lanfranco, and A. Palmisano, "Development and validation of a crank-angle model of an automotive turbocharged engine for HIL applications," Energy Procedia, vol. 45, pp. 839-848, 2014.

[24] F. G. Chmela and G. C. Orthaber, "Rate of heat release prediction for direct injection diesel engines based on purely mixing controlled combustion," SAE Paper 1999-010186, SAE International, 1999.

[25] N. H. Walke, M. R. Nandgaonkar, and N. V. Marathe, "Prediction of soot and NOx emissions for common rail diesel engines operating under transient conditions," International Review of Mechanical Engineering, vol. 8, no. 5, pp. 884-892, 2014.

[26] W. Annand, "Heat transfer in the cylinders of reciprocating internal combustion engines," Proceedings of the IMechE, vol. 177, pp. 973-980, 1963.

[27] P. Tamilporai, N. Baluswamy, P. M. Jawahar et al., "Simulation and analysis of combustion and heat transfer in low heat rejection diesel engine using two zone combustion model and different heat transfer models," SAE Technical Paper 2003-011067, 2003.

[28] M. Andersson, B. Johansson, A. Hultqvist, and C. Nohre, "A real time NOx model for conventional and partially premixed diesel combustion," SAE Paper 2006-01-0195, SAE International, 2006.

[29] H. Hiroyasu and T. Kadota, "Models for combustion and formation of nitric oxide and soot in direct injection diesel engines," SAE Technical Paper 760129, 1976.

[30] E. G. Pariotis, D. T. Hountalas, and C. D. Rakopoulos, "Sensitivity analysis of multi-zone modelling for combustion and emissions formation in diesel engines," SAE Paper 2006-011383, SAE International, 2006. 
[31] N. H. Walke, M. R. Nandgaonkar, and N. V. Marathe, "Prediction of combustion pressure, NOx and soot for D.I. Diesel engine by simplified model," in Proceedings of the ASME 2013 International Mechanical Engineering Congress and Exposition (IMECE '13), paper IMECE 2013-62067 pages, San Diego, Calif, USA, November 2013.

[32] E. C. Andrea, F. Alessandro, and S. Ezio, "Numericalexperimental study and solutions to reduce the dwell time threshold for fusion-free consecutive injections in a Multijet solenoid-type C.R. system," in Proceedings of the ASME Internal Combustion Engine Division Spring Technical Conference (ICES '06), Paper no. ICES2006-1369, pp. 317-332, Aachen, Germany, May 2006. 


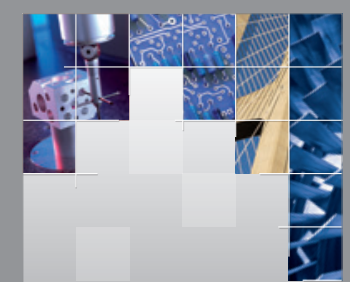

\section{Enfincering}
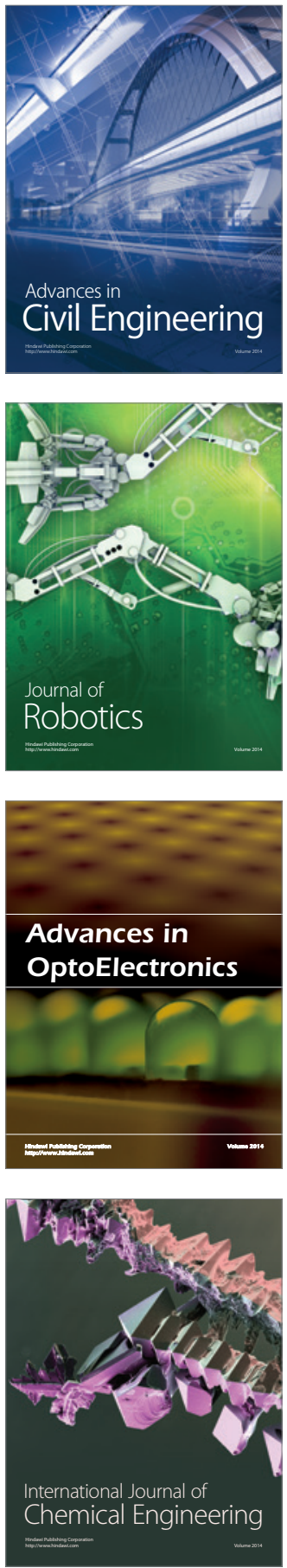

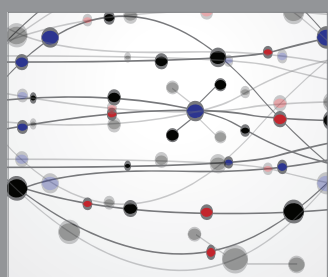

The Scientific World Journal

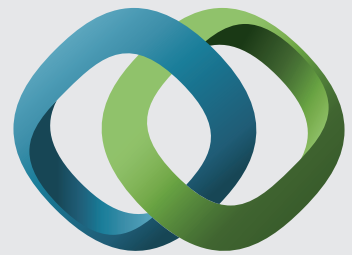

\section{Hindawi}

Submit your manuscripts at

http://www.hindawi.com
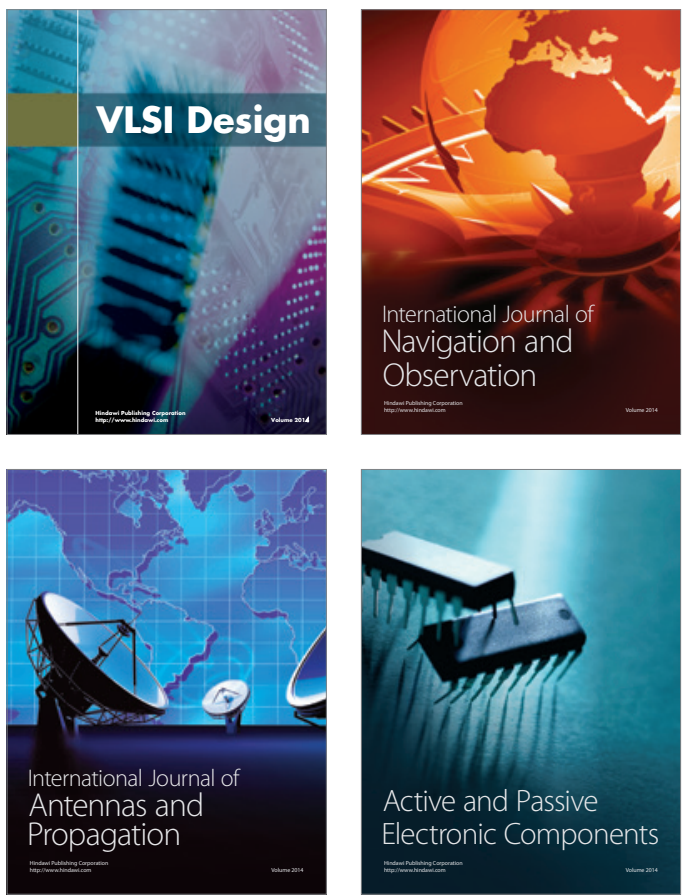
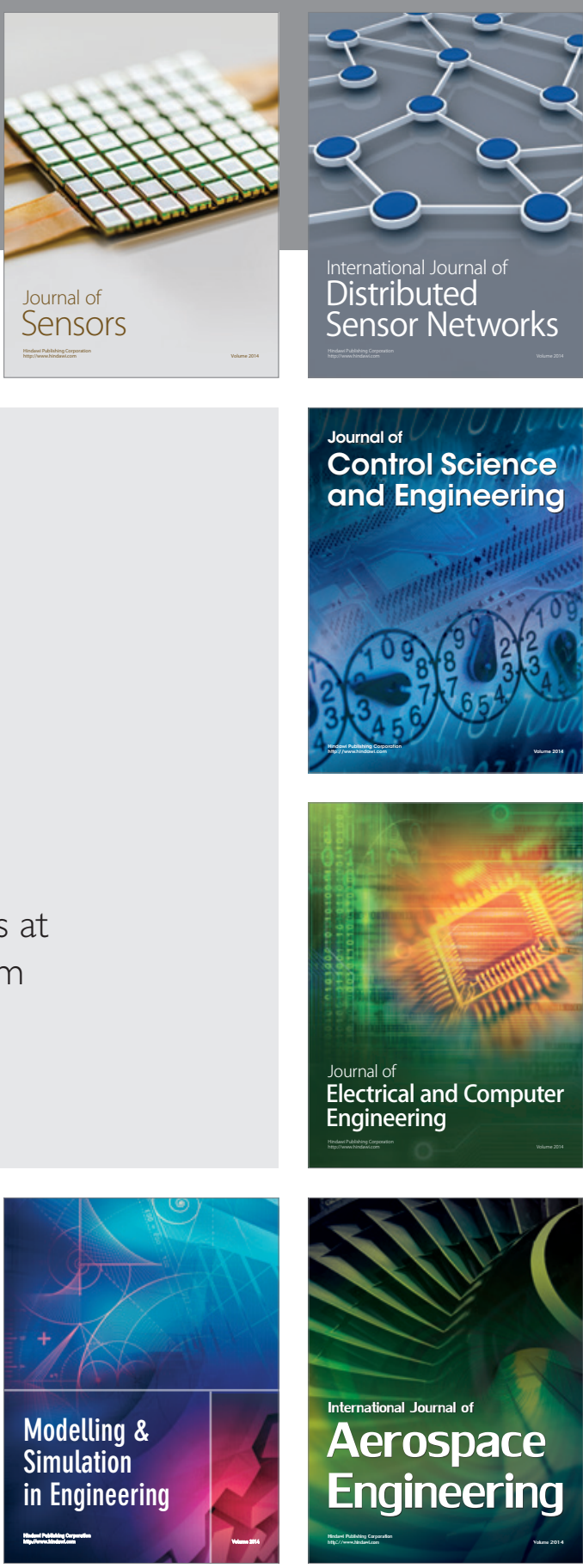

International Journal of

Distributed

Sensor Networks

Journal of

Control Science

and Engineering
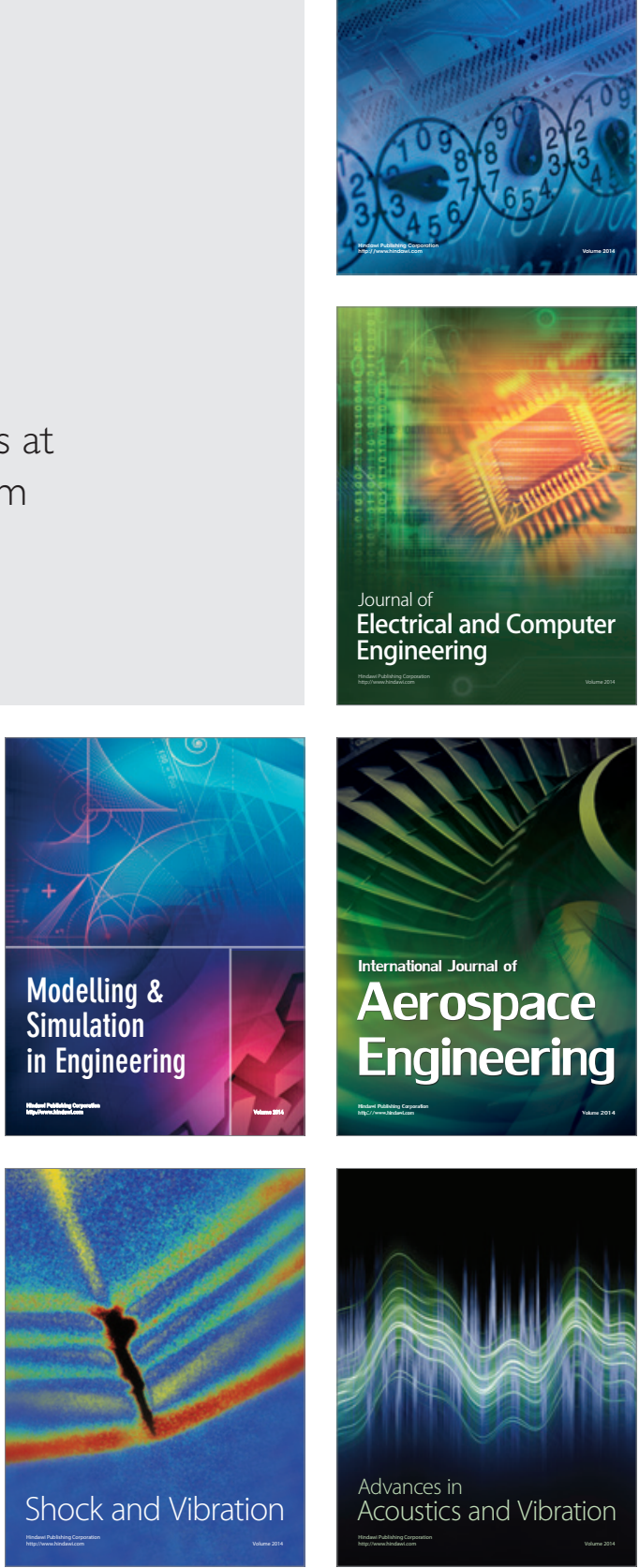